\title{
PERSPECTIVAS DE SUCESSÃO EM PROPRIEDADES DE PECUÁRIA FAMILIAR NO MUNICÍPIO DE DOM PEDRITO - RS
}

\author{
A. MATTE $^{1^{*}}$, R. M. SPANEVELLO ${ }^{2}$ e T. ANDREATTA ${ }^{2}$ \\ ${ }^{1}$ Universidade Federal do Rio Grande do Sul (UFRGS) \\ ${ }^{2}$ Universidade Federal de Santa Maria (UFSM) \\ alessandramatte@yahoo.com.br
}

Artigo submetido em fevereiro/2014 e aceito em fevereiro/2015

DOI: 10.15628/holos.2015.1964

\section{RESUMO}

Os pecuaristas familiares são um tipo de produtor com importância social e econômica significativa na Campanha do Rio Grande do Sul. Este estudo tem como objetivo analisar as perspectivas de continuidade das propriedades através da sucessão na concepção dos filhos de pecuaristas familiares, residentes no município de Dom Pedrito (RS). Para alcançar o objetivo proposto, foram entrevistados nove filhos de pecuaristas familiares que residem com os pais. As entrevistas continham questões de natureza qualitativa, relativas ao interesse dos filhos em dar continuidade à propriedade. Considerando os filhos de pecuaristas familiares entrevistados, os resultados apontam para o desinteresse dos mesmos em continuar investindo na propriedade, o que tende a ocasionar uma descontinuidade na sucessão da pecuária familiar em Dom Pedrito. Neste sentido, além da perda da reprodução social das famílias, também tende a ocorrer à perda de saberes locais de produção pecuária, bem como de um estilo de vida próprio deste tipo de produtores. Evidenciam-se incertezas quanto às próximas gerações de pecuaristas, àqueles que permanecerem se sobreviverão e de que forma. Esta problemática afeta não somente de forma individual cada família, mas também a comunidade e o setor público do município.

PALAVRAS-CHAVE: Pecuária familiar, sucessão, filhos, patrimônio.

\section{PERSPECTIVES OF SUCCESSION ON PROPERTY FAMILY LIVESTOCK FARMING THE MUNICIPALITY OF DOM PEDRITO - RS}

\begin{abstract}
Ranchers are a family type of producer with significant social and economic importance in the campaign of Rio Grande do Sul. This study aims to analyze the prospects for continuity of properties through the succession in the design of the children of family farmers, resident in Dom Pedrito (RS). To achieve our objective, we interviewed nine children of family farmers who live with their parents. The interviews contained questions of a qualitative nature relating to the interest of children in continuing the property. Whereas the children of farmers interviewed relatives, the results point to the
\end{abstract}

same lack of interest in continuing to invest in property, which tends to cause a discontinuity in the succession of family farming in Dom Pedrito. In this sense, besides the loss of social reproduction of families, also tends to result in loss of local knowledge of livestock production, and an own lifestyle this type of producers. Remarkable uncertainty about the next generation of farmers, those who remain, to survive and in what form. This problem affects not only the shape of individual families, but also the community and the public sector of the city.

KEYWORDS: Family livestock farming, succession, sons, property. 


\section{INTRODUÇÃO}

A região sul do Rio Grande do Sul apresenta uma realidade diferenciada em termos de estrutura fundiária, de formação cultural e de tipo de agricultor familiar (RIBEIRO, 2009). Nesta região, a visão do rural predominante é a de propriedades compostas por grandes extensões de áreas, ocorrendo o predomínio das estâncias típicas de pecuária extensiva, das lavouras de arroz e das fazendas de criação de gado, intensivas em tecnologias e de caráter empresarial.

No entanto, trabalhos realizados por Ribeiro $(2001 ; 2003 ; 2009)$ dão conta de demonstrar a diversidade e a heterogeneidade das formas de ocupação da parte sul do Rio Grande do Sul, especialmente na Campanha1. Apesar de pequenas áreas, estes estabelecimentos se dedicam à bovinocultura de corte em combinação com outras atividades, tendo a utilização, predominantemente, de mão-de-obra familiar (NESKE, 2009; RIBEIRO, 2009). Deste modo, este tipo diferenciado de produtores vem sendo denominado de "pecuaristas familiares".

Atualmente, os pecuaristas familiares no Rio Grande do Sul, contabilizam aproximadamente 45.000 famílias (cerca de $10 \%$ dos produtores rurais do estado). Em torno de 10.000 famílias (22 \%) ocupando parcela importante da Campanha do Rio Grande do Sul, no chamado Bioma Pampa (EMATER, 2010).

De um modo geral, existe uma carência de produção científica voltada aos aspectos sociais dos pecuaristas, refletindo no pouco conhecimento sobre a questão sucessória nas regiões de pecuária. Parte dos estudos referentes ao tema da sucessão são recentes no Brasil, especialmente na região Sul, e tem o foco mais voltado para a agricultura familiar.

Embora estes estudos sejam extremamente válidos, servindo como referências para outros referentes à reprodução social, tornam-se insuficientes para explicar a realidade sucessória das regiões de pecuária familiar. Isto se deve ao contexto da pecuária, distinto da agricultura familiar, e às mudanças estruturais, sociais e econômicas que vem atingindo o meio rural da Campanha do Rio Grande do Sul, tendendo a impactar na permanência das gerações mais novas no meio rural. Estudo realizado por Ribeiro (2009), considerando especificamente pecuaristas familiares da Região da Campanha, identificou, entre o conjunto de pecuaristas considerados na amostra, o envelhecimento desse tipo de produtor. Isso, em parte, se deve pela migração da população jovem para o meio urbano, dando evidências da problemática sucessória na pecuária familiar.

Apesar de um conjunto de políticas públicas que vem sendo desenvolvidas para auxiliar as populações mais vulneráveis, a migração da população rural brasileira tem se intensificado nas últimas décadas. De acordo com um estudo do Ministério do Desenvolvimento Agrário (2011), a população rural tem reduzido significativamente a partir da década de 1990. No ano de 1991 o

\footnotetext{
${ }^{1}$ A Fundação de Economia e Estatística (FEE) do Rio Grande do Sul organiza e agrupa os municípios em Conselhos Regionais de Desenvolvimento (COREDEs), com o objetivo desenvolver uma divisão regional para servir como subsídio para a alocação de políticas e ações de desenvolvimento regional. Dentre eles há o COREDE Campanha, formado por sete municípios que possuem a atividade pecuária como principal atividade produtiva, sendo eles: Aceguá, Bagé, Caçapava do Sul, Candiota, Dom Pedrito, Hulha Negra e Lavras do Sul. Trata-se de uma região inserida no contexto do Bioma Pampa. Nos últimos anos, em decorrência da reversão dos sistemas de produção (implementação de florestas cultivadas, inserção do cultivo da soja e aumento das áreas de arroz) tem reduzido significativamente as áreas ocupadas com campo nativo, característicos desse Bioma.
} 
percentual de população rural brasileira estava em torno de $24,7 \%$, reduzindo para $15,8 \%$ no ano de 2010. Segundo a Fundação de Economia e Estatística - FEE (2003), no Rio Grande do Sul, no período de 1991-2000, presenciou-se no meio rural um decréscimo de 272.314 habitantes, expresso na taxa de $-1,5 \%$ ao ano.

Uma das especificidades deste processo migratório é a saída mais acentuada da população jovem e feminina. Isso significa dizer que nem todo rapaz ou moça de origem rural tende a ser agricultor ou pecuarista familiar. De forma mais específica, o município de Dom Pedrito teve redução de 70\% de sua população rural no período de 1970 a 2010 (IBGE, 2010). Alguns estudos realizados no âmbito da agricultura familiar destacam que os motivos para desistência tendem a ser diversos, tanto de ordem interna a propriedade e a família, como externa (BRUMER; SPANEVELLO, 2008). Frente às possibilidades de ter ou não sucessores, surgem os questionamentos sobre como procederão os pais quanto ao destino do patrimônio e o que esperam da velhice, especialmente se não tiverem sucessores na propriedade para amparálos (SPANEVELLO, 2008).

Diante do exposto, a realização desse estudo tem como propósito detalhar a reprodução e a continuidade das famílias de pecuaristas familiares, a partir das perspectivas sucessórias dos filhos que ainda permanecem na propriedade familiar rural no município de Dom Pedrito, Rio Grande do Sul. A partir desta questão central, complementa-se a análise da dinâmica sucessória com a verificação das características dos filhos que permanecem no meio rural. De forma mais concreta, o objetivo desse estudo foi estudar o processo de saída dos filhos e filhas e as perspectivas destes quanto à continuidade da propriedade.

O artigo está composto por três seções, além desta introdução. A primeira seção contempla uma revisão que engloba conceituação do termo pecuária familiar e uma discussão acerca da reprodução social e sucessão familiar. A segunda seção procura apresentar brevemente a metodologia utilizada para a coleta empírica dos dados. Na sequência, a terceira seção enfoca na análise dos dados da pesquisa referente às características dos entrevistados e a percepção destes filhos em dar continuidade à propriedade, bem como os fatores motivacionais da saída dos jovens. Por fim, são apresentadas algumas as considerações embasadas nos resultados desse estudo.

\section{PECUÁRIA FAMILIAR E REPRODUÇÃO SOCIAL}

\subsection{Identificando a pecuária familiar}

Estudos como os de Abreu (2005; 1994), Lamarche (1993) e Anjos (1995) têm demonstrado como, em um mesmo lugar ou em um mesmo modelo de funcionamento, os agricultores familiares diferem significativamente conforme suas condições objetivas de produção. A conjugação de diversas características, ou seja, o fato de uma estrutura produtiva associar família-produção-trabalho tem consequências fundamentais na forma como ela age econômica e socialmente.

Ao analisar a formação histórica do estado do Rio Grande do Sul, Reverbel (1986) conclui que o manejo da terra, a forma de trabalho e os papéis dos membros da família assumem, no tempo e no espaço, uma diversidade de formas sociais para cada uma das condições. Os 
pecuaristas familiares, enquanto um tipo de produtor familiar apresentam particularidades relacionadas às características ambientais em que estão inseridos. Ocorre que a pecuária familiar surge como um novo tipo de produtor dentro da ideia de agricultores familiares. Diante disso, a pecuária surge como uma nova categoria dentro da ideia de agricultores familiares. Os pecuaristas familiares não são apenas os produtores que possuem bovinos de corte em pequenas áreas, mas sim uma combinação de atividades relacionadas a uma diversidade de outros fatores (RIBEIRO, 2009).

A metade sul do Rio Grande do Sul apresenta uma realidade diferenciada em termos de estrutura fundiária, de formação cultural e de tipo de agricultor familiar. Cotrim (2003) constata que os pecuaristas familiares têm características de agricultores familiares, entre elas pode ser elencadas: a gestão da unidade de produção feita pela família e a mão-de-obra familiar predominante. O trabalho de Miranda (2000) destaca, entre os pecuaristas familiares estudados, o alto grau de participação da mão-de-obra familiar (83\%) em relação à mão-de-obra total, os altos índices de lotação animal e a participação significativa das aposentadorias na composição da renda (46\% dos produtores recebem aposentadoria). Para Neske (2009), os sistemas produtivos destes pecuaristas são caracterizados pela combinação de sistemas de criação de pequena escala, porém, diversificados (bovinos, ovinos, caprinos, aves, porcos), e também por pequenos sistemas de cultivos voltados basicamente para a subsistência (feijão, milho, batatadoce, mandioca, etc.).

A pecuária familiar é denominada desta forma por conta da principal atividade realizada por estas famílias: a pecuária de corte. Ribeiro (2009) levanta algumas características que os diferencia da concepção geral de agricultura familiar, sendo elas:

a) Bovinocultura de corte como a principal atividade agrícola, praticada sobre pastagens naturais e com baixo uso de insumos externos sendo os bovinos considerados como mercadorias de reserva;

b) Autonomia em relação ao mercado, estabelecendo estratégias de comercialização a partir das necessidades da família e não na busca de melhores preços, além de distância dos endividamentos;

c) Uso principal da mão-de-obra da família associada com uma troca de serviços com os vizinhos em uma relação de reciprocidade que permite enfrentar os momentos de maior demanda por mão-de-obra;

d) Grande quantidade e grande importância da aposentadoria rural para os pecuaristas familiares;

e) Presença do autoconsumo de maneira significativa representada não pelo consumo de vegetais, mas pelo consumo de carne bovina e, principalmente, ovina.

Ainda que os pecuaristas familiares possuam características específicas, se comparados com as demais categorias de agricultores, em larga medida, não só são relevantes apenas os fatores produtivos, mas também socioeconômicos e comportamentais que influenciam na forma como os pecuaristas se organizam frente às restrições e possibilidades internas e externas aos estabelecimentos. De um modo geral, o inter-relacionamento destes aspectos tende a direcionar 
as decisões tomadas não só em relação à organização produtiva, mas também no que se refere à sucessão das propriedades e, consequentemente, à reprodução social da família.

\subsection{Reprodução social e sucessão}

De acordo com Almeida (1986) a reprodução social da família tende a obedecer dois movimentos: a reprodução anual ou de ciclo curto, e a reprodução geracional ou de ciclo longo. A reprodução de ciclo curto compreende a combinação de fatores relativos ao trabalho, conhecimento tradicional e recursos naturais para atender ao consumo familiar e repor os insumos necessários para o reinício do processo produtivo. De forma geral, o autor relaciona a reprodução de ciclo curto com a lógica econômica da família, englobando elementos como trabalho e consumo.

A reprodução de ciclo longo envolve aspectos do ciclo geracional e de como as famílias se perpetuam ao longo dos anos. A perspectiva de perpetuação da família é baseada em aspectos relacionados ao nascimento, casamento, morte e herança (ALMEIDA, 1986). Na reprodução de ciclo longo também podem ser acrescentadas as questões relativas à formação das novas gerações de agricultores, como a sucessão e a retirada dos pais do comando do estabelecimento. Apesar da terminologia ciclo curto e longo possuir certa recorrência em estudos sobre a sucessão rural cabe questioná-la frente à conjuntura contemporânea, haja vista a diversidade dos meios e modos de vida das famílias de agricultores familiares, que, frente às mudanças sociais, econômicas e produtivas, tem adotado distintas formas de reprodução que não seguem, necessariamente, a lógica proposta por Almeida (1986).

Considerando especificamente a reprodução de ciclo longo, observa-se que tradicionalmente, as propriedades rurais se reproduziam com base na permanência dos filhos no lugar dos seus pais, através do processo de transferência do controle e da gestão ou da sucessão familiar (GASSON; ERRINGTON, 1993). Para Gasson e Errington (1993), a reprodução social de longo prazo, é um processo que envolve a sucessão, a herança e a aposentadoria dos pais da atividade; neste caso a sucessão é entendida como a transferência do controle ou do gerenciamento sobre o uso do patrimônio familiar aos filhos sucessores ou à próxima geração. É através da característica referente à passagem do patrimônio e da gestão do estabelecimento familiar ao longo das gerações que a pecuária familiar assegura a sua reprodução social ou a sua continuidade. Nessa perspectiva, assegurar a transmissão do patrimônio entre os descendentes é uma forma de garantir a sucessão. A herança trata da transferência legal do patrimônio, inclusive a terra. A retirada ou aposentadoria dos pais significa a retirada do atual proprietário do trabalho e do comando do estabelecimento (GASSON; ERRINGTON, 1993), ou seja, depois de uma série de transições levam à aposentadoria integral e à saída da atividade e até mesmo da propriedade (LOBLEY, 2010).

Passa a ser entendida por sucessão a transferência do controle ou gerenciamento dos negócios e do patrimônio aos filhos sucessores ou à próxima geração (GASSON; ERRINGTON, 1993). Para Lobley (2010, p. 839), a sucessão é o "processo de transferência de controle gerencial e de outros ativos intangíveis, como conhecimento local específico". Para Lobley (2010), a sucessão intergeracional representa a renovação da propriedade familiar e pode potencialmente funcionar como um útil corretivo para enfrentar o envelhecimento cada vez mais crescente entre os agricultores e a população rural. Desse modo, a sucessão representa a continuidade da 
atividade produtiva, assegura a passagem do patrimônio à próxima geração, pode garantir cuidado aos pais quando chegarem à velhice impede o esvaziamento das comunidades rurais e o isolamento daqueles que permanecem, e pode contribuir com a produção para o consumo local. Ainda nesse sentido, Lobley (2010) aponta que a sucessão deve representar elemento de significativa importância para os formuladores de políticas públicas, dada a evidência desse processo na influência sobre o comportamento e a tomada de decisão dos agricultores e a capacidade de resposta a determinadas medidas políticas.

De maneira geral, o padrão sucessório predominante privilegia a seletividade ou escolha de um único sucessor pelos pais, e a exclusão dos demais como forma de garantir a continuidade dos estabelecimentos (CARNEIRO, 2001; RAMOS, 2004). O pai não define apenas o sucessor, mas encaminha profissionalmente os demais filhos e garante a continuação da produção e do estabelecimento por mais uma geração (CARRIERI; AGUIAR, 1993). Para formar as novas gerações, os pais asseguravam a instalação dos filhos através da repartição das áreas e determinavam um sucessor que iria assegurar a continuidade da propriedade e da sua ocupação (ABRAMOVAY et al., 1998). Ainda segundo esse autor, aos filhos cabia aceitar a decisão paterna e a ocupação de agricultor.

De acordo com Spanevello (2008), as famílias objetivam manter a sua reprodução usando estratégias ou respostas, frente às pressões macroeconômicas capitalistas (como os preços dos produtos agrícolas), políticas e a excessiva fragmentação das áreas pela herança que podem inviabilizar a continuidade dos grupos domésticos. Em síntese, há um movimento interno das famílias, visando manter e assegurar a transmissão do estabelecimento familiar. Nestes casos, a saída dos filhos ou de alguns deles para seguir em outras profissões ou mesmo para ser agricultor em outro local faz parte das estratégias familiares para garantir a continuidade do estabelecimento familiar (WOORTMANN, 1995).

$\mathrm{Na}$ atualidade, os padrões de referência em torno da sucessão vêm passando por mudanças, como mostra Carneiro (1999), Silvestro et al. (2001) e Spanevello (2008). Segundo esses autores, as mudanças estruturais na sociedade em geral, desde a questão da renda, da penosidade do trabalho agrícola, da desvalorização da ocupação, da falta de lazer no meio rural e da autonomia na gestão da propriedade, entre outros, geram implicações na sucessão das propriedades rurais. Dentre todos os fatores, o estudo é apontado, de forma mais relevante, como um fator externo que não oferece apenas informações, conhecimento, mas aciona o comparativo entre os modos de vida oferecidos pelo meio rural em contraponto ao meio urbano (BRUMER; SPANEVELLO, 2008). Ainda nas palavras das autoras, o estudo representa para os filhos o acesso aos empregos urbanos ou alternativas de vida que não fazem parte da realidade do meio rural, por isso, parte significativa dos jovens que saem para estudar buscam o ensino superior.

Independentemente dos fatores capazes de motivar os jovens a deixar o meio rural, o fato é que hoje as novas gerações estão mais voltadas a reproduzir os projetos individuais e não necessariamente os coletivos familiares. Nesse sentido, a decisão dos pais pelo sucessor está diretamente relacionada com a própria vontade do filho em ficar e assumir a propriedade. Há a incorporação de uma nova postura em relação aos valores aprendidos com a família, caracterizada pela sobreposição do individual sobre o coletivo, assim como sobre a relação simbólica entre a família, a terra e o trabalho, tal como afirma Woortmann (1995). 
Com a partida dos filhos, o planejamento sucessório articulado pelos pais fica incerto, podendo levar os pais a construir outros destinos, ou melhor, a partir da interrupção da lógica da passagem do patrimônio de geração a geração. Em estudo realizado por Matte et al. (2010), no noroeste do estado do Rio Grande do Sul, aponta que os pais sem sucessores tomam novos encaminhamentos para a propriedade, quais sejam:

a) Deixar para os filhos, no intuito de garantir os cuidados na velhice;

b) Vender a propriedade, na perspectiva do não retorno dos filhos.

Os dados desta pesquisa revelam que um dos resultados desta migração dos filhos é a mudança em torno da transmissão do patrimônio. A ausência de sucessores, além de comprometer a continuidade da propriedade, ocasiona um esvaziamento populacional, tanto nas propriedades como nas comunidades rurais, como também mostram os estudos de Brumer e Spanevello (2008) e Silvestro et al. (2001).

Em resumo, torna-se necessário entender as dimensões de dois processos interligados: ter ou não sucessor e os encaminhamentos relativos à transmissão do patrimônio para cada um desses casos.

\section{PROCEDIMENTOS METODOLÓGICOS}

O estudo foi realizado no município de Dom Pedrito, estado do Rio Grande do Sul - Brasil, no ano de 2010 (Figura 1). O município possui área territorial de $5.192 \mathrm{~km}^{2}$ (FEE, 2009), sendo o quarto maior município do estado. A escolha deste município ocorreu pela evidente presença da problemática de descontinuidade sucessória e redução desta população no meio rural, além da presença mais intensa de pecuaristas familiares (EMATER, 2010), estando ainda inserido no Bioma Pampa ${ }^{2}$.

De acordo com a FEE (2007), Dom Pedrito possui um PIB per capita de $\mathrm{R} \$ 12.208,00$ reais, atingindo um PIBpm de R\$ 465.711.000,00. Segundo o Censo Populacional de 2010 (IBGE, 2010), o município possui atualmente 38.916 habitantes, sendo que $90,64 \%$ (35.275) destes residem no meio urbano e apenas $9,36 \%$ (3.641) residem no meio rural.

Estes dados diferem significativamente das décadas passadas, como, por exemplo, no ano de 1970 , quando essa diferença era significativamente menor, havendo $37 \%$ da população no meio rural e $63 \%$ no meio urbano (IBGE, 2000). Observa-se que, desde então, a população urbana do município teve um aumento de $74 \%$, distintamente da população rural que reduziu $70 \%$ (IBGE, 2010). Fica evidente que há uma saída significativa de pessoas do meio rural.

O grupo que apresenta redução mais acentuada no rural do município são os jovens. Atualmente, Dom Pedrito possui apenas 768 jovens residindo no meio rural, uma redução de $67 \%$ em relação à década de 1970 (IBGE, 2000). A escolha da realização deste estudo nesta área se justifica devido a consequências econômicas e sociais que a evasão da população rural vem

\footnotetext{
${ }^{2}$ O Bioma Pampa é único no mundo, abrangendo parte significativa do Rio Grande do Sul, Uruguai e Argentina, sendo esse bioma reconhecido como um grande produtor de carnes, provenientes de seus campos naturais (SUERTEGARAY, PIRES DA SILVA, 2009). Ainda não se tem certeza do total de espécies animais e vegetais presentes na composição do bioma, porém há um consenso quanto a sua vasta diversidade de fauna e flora. Bilenca e Miñarro (2004), estimam que haja aproximadamente 3.000 plantas vasculares, 385 espécies de pássaros e 90 mamíferos terrestres, sobre a área que abrange o bioma Pampa.
} 
causando à região, interferindo no planejamento político e social das entidades envolvidas com este público.

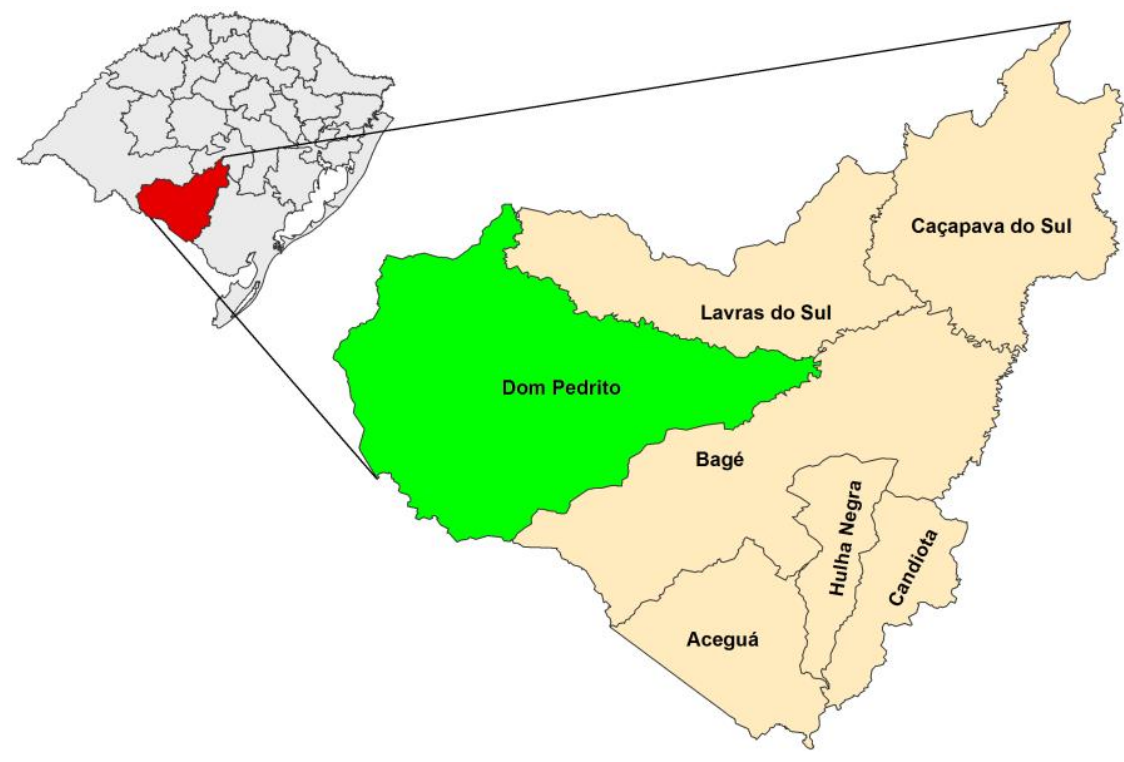

Figura 1: Mapa do COREDE Campanha, com destaque ao município de Dom Pedrito. Fonte: Elaboração dos autores.

No que concerne especificamente à pesquisa, primeiramente foram identificados filhos de pecuaristas familiares representativos da problemática estudada no município através de colaboração da Empresa de Assistência Técnica e Extensão Rural do Governo do Rio Grande do Sul (EMATER/RS) e do Sindicato dos Trabalhadores Rurais de Dom Pedrito/RS. A coleta de dados ocorreu no período de agosto a setembro de 2010, através de um roteiro de entrevista, aplicado individualmente a nove filhos e filhas de pecuaristas familiares. O referido roteiro contém questões referentes às características dos entrevistados, às problemáticas que interferem na permanência destes na propriedade e às perspectivas de permanência na ocupação de pecuarista familiar. As entrevistas foram realizadas, em sua maioria, nas propriedades rurais, possibilitando visualizar de forma mais clara a realidade das propriedades, bem como costumes, culturas, hábitos entre outras características particulares dos pecuaristas familiares. O número de entrevistados se justifica pela saturação das respostas.

\section{RESULTADOS E DISCUSSÕES}

Os resultados estão apresentados em três subitens: caracterização dos filhos e da propriedade, fatores que influenciam a permanência dos jovens no meio rural e o encaminhamento da propriedade e as perspectivas sucessórias para os entrevistados.

\subsection{Caracterização dos filhos e da propriedade}

Os filhos ainda presentes na propriedade se encontram na faixa etária entre os 17 e 38 anos, sendo $78 \%$ deles solteiros. Nesta condição, verifica-se que um dos filhos entrevistados, que já constitui família, trabalha na campanha e permanece lá quando há necessidade, porém, passa os finais de semana no meio urbano com esposa e filho. 
Quanto ao sexo dos entrevistados, $22 \%$ são do sexo feminino e $78 \%$ masculino. Conforme esse dado é possível observar entre os entrevistados um reduzido número de mulheres que ainda permanecem no meio rural, corroborando com os dados do Censo Populacional, sendo essa uma das causas da consequente redução de casamentos. Estes filhos possuem distintos graus de escolaridade, como pode ser visualizado na Tabela 1.

Tabela 1: Nível de escolaridade dos entrevistados.

\begin{tabular}{lcc}
\hline & Valor Absoluto & Valor Relativo (\%) \\
\hline Ensino Fundamental Incompleto & 2 & 22,22 \\
Ensino Fundamental Completo & 2 & 22,22 \\
Ensino Médio Incompleto & 1 & 11,11 \\
Ensino Médio Completo; & 2 & 22,22 \\
Superior Incompleto & 2 & 22,22 \\
Total & 9 & 100,00 \\
\hline
\end{tabular}

Fonte: Dados da pesquisa de campo.

Entre os filhos entrevistados, $44 \%$ deles estão estudando atualmente. Os dois jovens que são estudantes universitários fazem cursos afins à atividade pecuária, o que permitiria aplicar os conhecimentos técnicos na própria propriedade familiar. Todos os entrevistados ressaltam a importância da presença de instituições de ensino que possibilitem a eles uma formação superior ligada à atividade pecuária. Assim com constatado por Matte et al. (2010), o estudo é visto como essencial, independente da permanência ou não no estabelecimento, tendo em vista as novas demandas tecnológicas e conhecimentos que a pecuária vem exigindo.

Apenas um dos entrevistados (12\%) realizou os estudos em escolas locais, ou seja, no meio rural, e, apesar de seguir residindo neste meio, sua família (esposa e filho) residem no meio urbano do município. Essa situação específica é possível em função da principal atividade desenvolvida na propriedade, a criação pecuária, permitindo ao jovem administrar o estabelecimento sem a necessidade e residir no meio rural, realizando visitas esporádicas à propriedade.

Dos entrevistados, $22 \%$ tiveram formação educacional em escolas no meio urbano (Tabela 2). Essa condição tem ocorrido pelas dificuldades em estudar no meio rural, reflexo, principalmente, da falta de escolas rurais. Neste sentido, as estratégias das famílias é enviar alguns dos seus membros para a cidade. Considerando a amostra, a maior parte da família destes jovens utilizou deste mecanismo de escape para propiciar a educação formal aos filhos, o qual consistia na saída da mãe e dos filhos ruma à cidade, até estes completarem os estudos. Neste tempo, o pai continuaria no meio rural, tornando-se o responsável pelo sustento da família na cidade.

Tabela 2: Tipo de Escola em que realizou a educação formal.

\begin{tabular}{lcc}
\hline & Valor Absoluto & Valor Relativo (\%) \\
\hline Escola pública local & 1 & 11,11 \\
$\begin{array}{l}\text { Escola pública urbana } \\
\text { Parte em escola pública no meio rural e parte no meio }\end{array}$ & 2 & 22,22 \\
$\begin{array}{l}\text { urbano } \\
\text { Total }\end{array}$ & 9 & 66,67 \\
\hline
\end{tabular}

Fonte: Dados da pesquisa de campo. 
O resultado desta mobilidade parcial da estrutura familiar explica a maior proporção de filhos que estudaram parte em escolas públicas do meio rural e parte em escolas públicas do meio urbano, totalizando $66 \%$ dos filhos entrevistados (Tabela 2). As evidências apontam que o acesso à educação formal foi e continua dificultando a permanência dos filhos na propriedade, pois causa o afastamento dos mesmos. Essa situação pode ser visualizada entre faixas etárias bem distintas, sendo que o problema é apontado tanto pelo filho mais velho como pelo mais novo. $O$ estudo também representa o acesso aos empregos urbanos ou alternativas de vida que não fazem parte da realidade do meio rural, por isso, uma parte significativa dos jovens que sai para estudar busca o ensino superior (BRUMER; SPANEVELLO, 2008).

Todas às propriedades realizam a criação de bovinos, sendo a principal atividade desenvolvida em $90 \%$ das propriedades. A ovinocultura, por sua vez, foi identificada em $90 \%$ das propriedades e, na maior parte dos casos, são utilizados para o consumo interno. Todos os animais são criados sobre as pastagens naturais do Bioma Pampa, havendo uma relação de troca entre as partes, o campo alimenta os animais, enquanto esses permitem a reprodução das plantas nativas. No que se refere à produção de cereais, o milho aparece em $55 \%$ das propriedades investigadas, porém a área utilizada para esta produção é significativamente reduzida, não sendo superior a 10 hectares. O cultivo da soja é pouco comum entre os pecuaristas familiares, sendo encontrada em apenas uma das propriedades entrevistadas. $O$ arroz, por sua vez, apesar de ser o cereal mais produzido na região em função das condições de solo e clima, não foi encontrado entre as propriedades pesquisadas. Isso é justificado pelos próprios entrevistados que apontam ser inviável a produção em uma pequena área, além de muitas das propriedades não possuírem água para a irrigação. Para $90 \%$ das famílias entrevistadas a principal fonte de renda é advinda exclusivamente da pecuária, enquanto para os $10 \%$ restantes esta fica dividida entre a pecuária e lavoura.

\subsection{Fatores que influenciam a permanência dos jovens no meio rural}

Na visão dos filhos entrevistados, existem fatores internos e externos à propriedade que afetam a decisão de permanecer ou não no meio rural como pecuaristas. Entre eles destacam-se: o matrimônio; a educação formal; a ausência de escolas técnicas; a redução da população rural; e a autonomia no interior da propriedade.

a) Matrimônio: O casamento, para os filhos, representa uma incerteza na permanência e continuidade da vida no meio rural. O desejo momentâneo dos filhos em permanecer pode ser influenciado pelo futuro(a) companheiro(a). Com o atual esvaziamento de jovens no meio rural, a tendência é que o candidato seja do meio urbano, o que tende a influenciar na decisão de onde fixar residência. Mesmo aqueles filhos que estão casados apontam indícios de incerteza na continuidade na atividade: "Eu amava a pecuária, mas na situação que estamos não dá." (Filho 06); "Eu queria poder crescer, desenvolver. O jovem quer crescer e a campanha não oferece isso." (Filho 02).

b) Acesso à educação formal: Apesar de essencial, pode ser considerado um agente motivador da saída dos filhos para os centros urbanos, seja para cidades maiores ou mesmo para a sede do município. Verifica-se um desejo, por parte de todos os filhos entrevistados, em continuar os estudos, sendo que $77 \%$ deles pretendem realizar uma especialização ou curso técnico que permita melhorar as atividades pecuárias. Nesse sentido, o estudo passa a 
representar um estímulo à permanência na propriedade familiar, como é constatado nas palavras dos próprios entrevistados: "Penso em uma hora dessas fazer um curso técnico para lidar [trabalhar] no campo com meu pai" (Filho 05); "Pretendo fazer faculdade e continuar aqui" (Filha 01); "Quero fazer veterinária ou pelo menos um [curso] técnico" (Filho 07).

O que limita este anseio de especializar-se é a ausência de escolas técnicas no município. Mesmo assim, 33\% dos entrevistados saíram do município para estudar em escolas técnicas agropecuárias ou zootécnicas e para a realização de outros cursos, como o de inseminação artificial que contribui para auxiliar na melhoria das condições produtivas da família.

No entanto, uma parcela maior de filhos sai e não retorna, como diz o Filho 04: "Eu fui e voltei, mas a maioria do pessoal que estava lá queria mesmo era sair de casa e achar um emprego, por isso estavam lá". De forma geral, os jovens apontam a escassez de opções de estudo como um aspecto a ser melhorado para a permanência dos jovens, demandando a criação de escolas técnicas e a ampliação e extensão de universidades federais, sendo essa última já presente no município.

c) Redução da população rural: Os espaços de lazer já não têm mais a mesma influência que em outros tempos. Isto porque a proximidade com a cidade tem suprido parte desta ausência no meio rural. Os jovens acreditam que a reestruturação de estabelecimentos que promovam o lazer (campos de futebol, salões de festas, entre outros) não teriam os resultados esperados, pois atualmente a população que está no meio rural é muito reduzida, e não seria suficiente para promover a utilização destes locais. O Filho 02 relata que "o problema para ter lazer na campanha [meio rural] teria que ter mais gente, sem gente na campanha não tem lazer", ressaltando a problemática da redução da população no meio rural. Atualmente, o lazer está ligado às atividades realizadas na propriedade, como, por exemplo, a marcação do gado (registro dos animais): "Meu lazer também é a campanha, me divirto muito lá" (Filho 09).

Nas condições atuais, em que a região da Campanha do Rio Grande do Sul vem sofrendo um esvaziamento contínuo, as atividades denominadas de lazer se concentram em algumas poucas cavalgadas e "carreiras"3.

A alternativa mais visualizada pelos filhos para reduzir a falta de atividades de lazer (festas, encontros, entre outros.) no meio rural, estão sendo as atividades oferecidas no próprio meio urbano do município. Diante disso, a cidade se torna o espaço do lazer, o que incentiva contribui ainda mais com a migração de jovens para os centros urbanos.

d) Autonomia no interior da propriedade: Dentre as atividades produtivas que estes filhos realizam, não há restrições de tarefas, eles atuam juntamente com a família em todas as atividades da propriedade, desde o manejo com os animais (bovinos e ovinos), bem como com a implantação de lavouras e a manutenção das instalações. Não se observa diferenciação na execução das atividades. No entanto, o tempo dedicado por cada membro na realização das atividades é distinto, isso acontece em função dos filhos estarem estudando ou possuírem família. Dessa forma, as atividades na campanha ficam limitadas em tempo, já que $78 \%$ dos filhos têm outras responsabilidades, além das atividades da propriedade.

\footnotetext{
${ }^{3}$ Carreiras são as corrida de cavalos realizadas nas próprias propriedades rurais, sendo, em sua maioria, organizadas pelos pecuaristas familiares.
} 
No que diz respeito às decisões referentes às atividades realizadas na propriedade, foi observado que os filhos não apresentam autonomia quanto à tomada de decisão, cabendo este papel ao pai e/ou chefe de família, conforme argumentam os próprios filhos: "Ele [pai] deixa eu [filho] fazer tudo, mas não da para fazer sem avisar. Tem que conversar" (Filho 05); "Eu ajudo tudo o meu pai. Participo e acompanho as negociações. Não tomo decisão sozinho, ainda." (Filho 09). Mesmo assim, os pais oferecem aos filhos alguns animais e a responsabilidade pelo controle de uma atividade, mas desde que está não seja a principal fonte de renda. Quando questionados sobre a possibilidade de introduzirem algo novo na propriedade, estes filhos afirmam que os pais dariam apoio, pois "iriam auxiliá-los, caso desejassem ficar".

\subsection{O encaminhamento da propriedade e as perspectivas sucessórias}

Nas famílias investigadas não houve ainda a escolha de um sucessor, de acordo com os jovens entrevistados. Porém, esses reconhecem que a possibilidade de assumirem a propriedade do pai é maior do que os demais irmãos, nos casos em que há mais filhos. Mesmo sabendo que receberão a propriedade como herança, os filhos não garantem que a administração também será repassada no mesmo momento. Nas palavras do Filho 07: "O pai vai administrar tudo. Nós podemos fazer e ter as coisas. Eu e meu irmão temos ovelha e boi, e agora eu quero colocar o tambo [produção de leite]. Mas é tudo do pai." Essa ideia de que o pai é o "dono" está bem clara para esses filhos, limitando-os a esperar sua parte (herança) e, somente após isso, administrarem na forma que desejam.

Quando questionados sobre a possibilidade de assumir a propriedade, $89 \%$ dos filhos acreditam que sim e apenas $11 \%$ não veem a possibilidade de assumir (Tabela 3 ). Porém, a hipótese de assumir a propriedade é visualizada nas condições em que o pai faltar ou quando este não tiver mais forças para prosseguir na administração e, consequentemente, realizar a passagem do patrimônio. É importante ressaltar que aqueles que pretendem ou gostariam de permanecer (89\%) não possuem certeza de que irão permanecer. Esta é a vontade momentânea desses filhos, todavia não é um desejo consolidado em bases firmes.

Tabela 3: Perspectivas sucessórias e suas possibilidades de concretização.

\begin{tabular}{lcc}
\hline & Valor Absoluto & Valor Relativo (\%) \\
\hline Acreditam na possibilidade de serem sucessores & 8 & 88,89 \\
Não acreditam na possibilidade de serem & & \\
sucessores & 1 & 11,11 \\
Total & 9 & 100,00 \\
\hline
\end{tabular}

Fonte: Dados da pesquisa de campo.

No decorrer da entrevista com os filhos, verifica-se que apesar de $89 \%$ deles desejarem ficar, apenas $50 \%$ destes pretendem permanecer realmente (Tabela 3), mesmo assim não assumem que exercerão exclusivamente a atividade pecuária. Diante disso, os filhos têm clareza que a administração da propriedade somente passará dos pais para eles quando os atuais gestores não puderem mais administrar. Isso tende a ocorrer mesmo nos casos em que os filhos têm interesse em permanecer, restando como alternativa buscar outras formas de adquirir área de terra e iniciar seu próprio negócio.

Nesse sentido, a canalização para a cidade tende a ocorrer entre os filhos de pecuaristas do município de Dom Pedrito. E para esses jovens, a possibilidade de retornar para a propriedade 
após a saída do meio rural é visualizada na fase da própria velhice, haja vista a pretensão de viver uma "vida tranquila", mas após construírem sua família distante do rural que atualmente se encontram.

A movimentação do meio rural para o meio urbano esta alicerçada à busca pela realização de sonhos e anseios dos filhos. Entretanto, os sonhos, tanto dos que pretendem permanecer como dos que pretendem sair, tem em comum o bem estar de suas famílias. Este bem estar, refere-se ao conforto necessário para viver bem, não almejando lucros extraordinários.

Além das dificuldades ressaltadas pelos jovens, surgem outras problemáticas que os afastaria da pecuária, dentre elas a desvalorização do produto pecuário, a baixa renda advinda da atividade, empecilhos na comercialização dos produtos que se tornam elementos importantes sobre a percepção das dificuldades de continuidade desses filhos. Mesmo assim, um dos entrevistados faz uma análise positiva das condições atuais do meio rural do município: "Antigamente não se tinha nada, hoje se tem tudo. Os filhos agora têm computador, luz em casa, água, tem tudo. Eu vejo as pessoas reclamar, mas tem tudo hoje." (Filho 01). Esta análise realizada pelo entrevistado é muito pertinente, pois demonstra a melhora em termos de acesso a meios e ferramentas importantes para as famílias, reduzindo cada vez mais as diferenças entre rural e urbano.

\section{CONSIDERAÇÕES FINAIS}

A migração da população rural, especialmente os jovens, vem ocorrendo de forma significativa nas últimas décadas. Além de causar um "esvaziamento" do campo, está mesma população pode enfrentar sérias dificuldades de reprodução social no meio urbano. Isso tende a ocorrer entre aqueles que estão situados na faixa etária mais elevada, devido à dificuldade de emprego, bem como de qualificação formal para atuar no setor industrial e de serviços.

Em linhas gerais, esse artigo buscou analisar a continuidade das famílias de pecuaristas familiares, a partir da percepção de filhos que ainda permanecem no meio rural do município de Dom Pedrito, no Rio Grande do Sul. O afastamento dos filhos das atividades da propriedade, bem como a ausência desses na tomada de decisões e na administração dos negócios, não os prepara mais para administrar a atividade produtiva realizada pela família, por consequência não os estimula a ver a vida no meio rural como viável e sustentável, no sentido de permitir a sobrevivência familiar.

Apesar de haver interesse em permanecer na propriedade, os filhos também procuram possibilidades de trabalho fora dela. Diante desse cenário, a ausência de sucessores tende a crescer ao longo do tempo, aumentando a distorção da velha ordem sucessória, onde filho de agricultor ou pecuarista naturalmente continuaria seguindo as atividades da família, ou seja, o jovem possuía grande probabilidade de seguir o ofício dos pais. Assim, ao olhar a estrutura das famílias de pecuaristas familiares investigadas surgem preocupações não somente no que diz respeito à reprodução social desta categoria e a sua permanência ao longo do tempo, mas também com o destino dos pais, que, diante dessa nova condição, tendem a ficar sozinhos na propriedade.

Em linhas gerais, além da importância socioeconômica dos pecuaristas familiares, esse tipo de produtor possui significativa relevância no que diz respeito à conservação do Bioma 
Pampa, pois desenvolvem sua atividade conservando e respeitando os limites da natureza. A presença de pecuaristas ativos, evita a supressão das áreas do bioma, uma vez que praticam a pecuária fazendo uso de pastagens naturais como principal alimento para os animais.

\section{REFERÊNCIAS BIBLIOGRÁFICAS}

1. ABRAMOVAY, R. et al. Juventude e agricultura familiar: desafios dos novos padrões sucessórios. Brasília: Unesco, 1998.

2. ABREU, L. S. A construção da relação social com o meio ambiente entre agricultores familiares da mata atlântica brasileira. Jaguariúna: Embrapa Meio Ambiente, 2005.

3. ABREU, L. S. Impactos Sociais e Ambientais na Agricultura: uma abordagem histórica de um estudo de caso. Jaguariúna: EMBRAPA-SPI, 1994.

4. ALMEIDA, M. W. B. de. Redescobrindo a família rural. Revista Brasileira de Ciências Sociais, São Paulo, v.1, n. 1, p. 66-83, jun. 1986.

5. ANJOS, F. S. dos. A agricultura familiar em transformação: o caso dos colonos-operários de Massaranduba (SC). Pelotas: Universitária, 1995.

6. BILENCA, D., MIÑARRO, F. Identificación de áreas valiosas de pastizal en las Pampas y Campos de Argentina, Uruguay y Sur de Brasil. Fundación vida silvestre. 323p. 2004

7. BRUMER, A.; SPANEVELLO, R. M. Jovens agricultores da Região Sul do Brasil. Porto Alegre: UFRGS; Chapecó: Fetraf-Sul/CUT, 2008. Relatório de Pesquisa.

8. CARRIERI, A, P; AGUIAR, A. R. C. A transferência de gestão em unidades de produção familiar: a sucessão e a herança no bairro rural de Cardoso (M.G.). In: ENCONTRO DA ASSOCIAÇÃO NACIONAL DE PÓS-GRADUAÇÃO E PESQUISA EM ADMINISTRAÇÃO, 17., 1993, Salvador. Anais... Salvador: Associação Nacional de Pós-Graduação e Pesquisa em Administração, 1993. CD ROM.

9. CARNEIRO, M. J. Herança e gênero entre agricultores rurais. Revista Estudos Feministas, Florianópolis, v. 9, n. 2, p. 22-55, jun./dez. 2001.

10. CARNEIRO, M. J. O ideal rurbano: campo e cidade no imaginário dos jovens rurais. In: SILVA, F. C. T (Org.). Mundo rural e política: ensaios interdisciplinares. Rio de Janeiro: Campus, 1999. p. 97-117.

11. COTRIM, M. S. "Pecuária familiar" na região da Serra do Sudeste do Rio Grande do Sul: um estudo sobre a origem a situação socioagroeconômica do pecuarista familiar no município de Canguçu - RS. Dissertação (Mestrado em Desenvolvimento Rural). Programa de PósGraduação em Desenvolvimento Rural, Universidade Federal do Rio Grande do Sul, Porto Alegre, 2003.

12. EMATER RS. Caracterização do pecuarista familiar da extensão rural no Rio Grande do Sul com vistas as ações para o desenvolvimento rural sustentável. Porto Alegre: EMATER/RS, 2010. (não publicado)

13. FUNDAÇÃO DE ECONOMIA E ESTATÍSTICA. Índice de desenvolvimento socioeconômico do RS (Idese) 1991-2000. Porto Alegre: FEE, 2003 (Documentos FEE, no 58) Disponível em: <http://www.fee.tche.br/sitefee/pt/content/estatisticas/pg_idese.php>. Acesso em: 25 abr. 2012. 
14. FUNDAÇÃO DE ECONOMIA E ESTATISTICA. Municípios, 2007. Disponível em: $<$ http://www.fee.tche.br/sitefee/pt/content/resumo/pg_municipios_detalhe.php?municipio =Dom+Pedrito>. Acesso em 25 abr. 2012.

15. FUNDAÇÃO DE ECONOMIA E ESTATISTICA. Municípios: Dom Pedrito, 2009. Disponível em: $<$ http://www.fee.tche.br/sitefee/pt/content/resumo/pg_municipios_detalhe.php?municipio =Dom+Pedrito>. Acesso em: 27 abr. 2012.

16. GASSON, R.; ERRINGTON, A. The farm family business. Wallingford: Cab International, 1993.

17. INSTITUTO BRASILEIRO DE GEOgrafiA e eStATístiCA. Censo da População, 2000. Brasília, 2000. Tabela 200. Disponível em: <http://www.sidra.ibge.gov.br/bda/tabela/listabl.asp?z= $\mathrm{t} \& \mathrm{c}=200>$. Acesso em: 10 mai. 2012.

18. INSTITUTO BRASILEIRO DE GEOGRAFIA E ESTATístICA. Dados do Censo 2010 Publicados no Diário Oficial da União do Dia 04/11/2010. BRASÍLIA, 2010. Disponível em: <http://www.ibge.gov.br/home/estatistica/populacao/censo2010/resultados_dou/default_r esultados_dou.shtm>. Acesso em: 16 MAl. 2011.

19. LAMARCHE, H. (Coord.). A agricultura familiar: comparação internacional. Campinas, Editora da UNICAMP, 1993. v.1, p. 13-34.

20. LOBLEY, M. Sucession in the family farm business. Journal of Farm Management, v.13, n.12, p. 839-851, 2010.

21. MATTE, A. et al. A reprodução social na agricultura familiar: a saída dos filhos e o encaminhamento do patrimônio entre agricultores sem sucessores. In: CONGRESSO DA SOCIEDADE BRASILEIRA DE ECONOMIA, ADMINISTRAÇÃO E SOCIOLOGIA RURAL, 48., 2010, Campo Grande. Anais... Campo Grande, 2010. CD ROM.

22. MINISTÉRIO DO DESENVLVIMENTO AGRÁRIO - MDA (2011). Estatísticas do Meio Rural 20102011. 4 Ed. Brasília. 2011.

23. NESKE, M. Z. Estilos de agricultura e dinâmicas locais de desenvolvimento rural: o caso da Pecuária Familiar no Território Alto Camaquã do Rio Grande do Sul. 2009. Dissertação (Mestrado em Desenvolvimento Rural). Programa de Pós-Graduação em Desenvolvimento Rural, Universidade Federal do Rio Grande do Sul, Porto Alegre, 2009.

24. RAMOS, G. Un acercamiento teórico a los efectos del sistema de sucesión en la incorporación de los jóvenes a la agricultura Vasca. Bilbao, 2004. Disponível em: <http://www.unavarra.es/puresoc/pdfs/c_ponencias/ramos.pdf>. Acesso em: 03 mai. 2012.

25. REVERBEL, C. O gaúcho. Aspectos de sua formação no Rio Grande e no Rio da Prata. Porto Alegre: L\&PM, 1986. 109 p.

26. RIBEIRO, C. M. Pecuária Familiar na região da Campanha do Rio Grande do Sul: definições e estratégias. Bagé: EMATER/ RS, 2001. (não publicado)

27. RIBEIRO, C. M. Pecuária Familiar na Região da Campanha do Rio Grande do Sul. Pecuária familiar. Porto Alegre: EMATER RS / ASCAR, 2003. p. 11-46. (Série Realidade Rural, 34)

28. RIBEIRO, C. M. Estudo do modo de vida dos pecuaristas familiares da região da campanha do Rio Grande do Sul. 2009. Tese (Doutorado em Desenvolvimento Rural). Programa de PósGraduação em Desenvolvimento Rural, Universidade Federal do Rio Grande do Sul, Porto Alegre, 2009. 
29. SILVESTRO, M. et al. Os impasses sociais da sucessão hereditária na agricultura familiar. Florianópolis: EPAGRI; Brasília: NEAD, 2001.

30. SPANEVELLO, R. M. A dinâmica sucessória na agricultura familiar. 2008. Tese (Doutorado em Desenvolvimento Rural). Programa de Pós-Graduação em Desenvolvimento Rural, Universidade Federal do Rio Grande do Sul, Porto Alegre, 2008.

31. SPANEVELLO, R. M. et al. As perspectivas sucessórias de gestão dos negócios do patrimônio entre agricultores familiares sem sucessores. Revista CCEI. v.14, n.26, ago. 2010. Bagé: URCAMP, 2010, pg. 54-71.

32. SUERTEGARAY, D. M. A.; PIRES DA SILVA, L. A.. Tchê Pampa: histórias da natureza gaúcha. In: PILLAR, V. P.; MÜLlER, S. C.; CASTILHOS, Z. M. de S.; JACQUES, A. V. Á. (Orgs.). Campos Sulinos - conservação e uso sustentável da biodiversidade. Brasília: Ministério do Meio Ambiente, 2009. p. 42-59.

33. WEISHEIMER, N. Caracterização dos jovens na agricultura familiar no Rio Grande do Sul. Porto Alegre: IFCH/UFRGS, 2007. Relatório.

34. WOORTMANN, E. Herdeiros, parentes e compadres: colonos do Sul e sitiantes no Nordeste. São Paulo: Hucitec; Brasília: Editora da UNB, 1995. 